\title{
Ecofisiologia da cana-de-açúcar no sub-bosque de canafístula em arranjos de sistema agroflorestal
}

\author{
Elvis Felipe Elli*, Braulio Otomar Caron, Gizelli Moiano de Paula, \\ Elder Eloy, Felipe Schwerz, Denise Schmidt
}

Universidade Federal de Santa Maria, Santa Maria, Brasil

*Autor correspondente, e-mail: elvisfelipeelli@yahoo.com

\begin{abstract}
Resumo
O objetivo deste trabalho foi avaliar aspectos fisiológicos e térmicos da cana-de-açúcar, em linhas orientadas ao Norte e Sul, no sub-bosque de canafístula em dois arranjos de plantas em sistema agroflorestal. O delineamento experimental utilizado foi de blocos completos casualizados, em esquema fatorial $2 \times 2 \times 6$, ou seja, dois sistemas agroflorestais (faixa e linha), duas linhas de avaliação (Norte e Sul) e seis horários do dia (9, 10, 12, 14, 15 e 16 h), com três repetições. As características avaliadas foram: radiação fotossinteticamente ativa (RFA) incidente, temperatura da folha (TF), resistência à difusão de vapor (RS) e transpiração (E), com uso de um porômetro digital LI-1600 LI-COR. A análise de variância revelou diferença na interação Sistema agroflorestal x Linha de avaliação x Hora do dia, para todas as variáveis analisadas. As características fisiológicas e térmicas da cana-de-açúcar são influenciadas pelo arranjo de plantas do sistema agroflorestal e pelo local de avaliação dentro do sistema. O sistema faixa, de modo geral, apresenta maior quantidade de RFA disponível em seu sub-bosque, o que reflete em aumento dos valores de RS e redução da $\mathrm{E}$ da cana-de-açúcar. A linha Sul apresenta maior E da cana-de-açúcar pela manhã no sistema faixa e menor a tarde no sistema linha, devido aos maiores valores de TF.
\end{abstract}

Palavras-chave: Radiação fotossinteticamente ativa, sombreamento, transpiração

\section{Ecophysiology of sugarcane in the understory of Peltophorum dubium Spr. in agroforestry systems arrangements}

\begin{abstract}
The objective of this study was to evaluate physiological and thermal aspects of sugarcane, in North and South oriented lines, in 'canafístula' understory under two plant arrangements in an agroforestry system. The experimental design was a completely randomized block in a 2x2x6 factorial, with two agroforestry systems (strip and line), two evaluation lines (North and South) and at six times a day (9am, 10am, 12pm, 2pm, 3pm and 4pm) with three repetitions. The evaluated characteristics were: incident photosynthetically active radiation (RFA), leaf temperature (TF), resistance to vapor diffusion (RS) and transpiration (E) using a digital porometer LI-1600 LI-COR. Analysis of variance revealed differences for the interaction of agroforestry system $x$ evaluation line $x$ time, for all variables. The physiological and thermal characteristics of sugarcane are influenced by plant arrangement, agroforestry system and the local evaluation within the system. The strip system lead to a higher available amount of RFA in its understory, which reflects in increased RS values and reduced $E$ of sugarcane. The South line presented higher $E$ for sugarcane in the morning period in strip system and lower during the afternoon for the line system, due to higher TF values.
\end{abstract}

Keywords: Photosynthetically active radiation, shading, transpiration 


\section{Introdução}

Os sistemas agroflorestais consistem no uso integrado da terra para fins de produção florestal, agrícola e animal. Esta integração vem trazendo inúmeros benefícios, como a recuperação de áreas degradadas, redução dos custos de produção, maior aporte de matéria orgânica, o que acarreta a melhoria dos atributos químicos, físicos e biológicos do solo (Tracy \& Zhang, 2008; Neves et al., 2009; Salton et al., 2013; Xavier et al., 2014).

A cana-de-açúcar (Saccharum officinarum L.) apresenta expressiva importância socioeconômica no Brasil, sendo que o sistema de monocultivo é predominante para a cultura. A sua inserção em sistemas agroflorestais é uma alternativa interessante, pelo fato dos mesmos serem considerados uma forma de produção alternativa, visando a preservação dos recursos naturais e o uso eficiente da terra.

O crescimento e desenvolvimento de diferentes espécies em uma mesma área, provocam interações dinâmicas na comunidade de plantas, que se alteram com o tempo. Em áreas onde há o componente arbóreo, ocorre crescimento contínuo em altura, projeção de copa e índice de área foliar (IAF), que modificam a distribuição dos recursos existentes no sistema (Müller et al., 2014).

A radiação solar, ao ser interceptada pelo dossel arbóreo, pode ser absorvida, transmitida ou refletida, dependendo do ângulo de incidência dos raios solares, ângulo de inserção foliar e IAF. A fração transmitida através da copa, disponível às plantas no interior do dossel, pode apresentar forma direta ou difusa, a qual condiciona o microclima interno do sistema, podendo afetar as características fisiológicas das espécies presentes no sub-bosque (Mendes et al., 2013).

A radiação solar pode variar em diferentes pontos dentro de um sistema agroflorestal (Paciullo et al., 2011), dependendo da área de sombra proporcionada pela copa, bem como da orientação e espaçamento entre as árvores. Estas características arbóreas podem interferir na velocidade e na direção do vento, modificando a renovação do ar na camada limítrofe da folha, a qual afeta o déficit de pressão de vapor (DPV) entre a folha e o ar (Taiz \& Zeiger, 2013).

A modificação do DPV pode afetar a taxa transpiratória e a resistência à difusão de vapor, as quais caracterizam o estado hídrico da planta. Estas variáveis apresentam diferenças de acordo com a espécie, idade da planta, condições de solo, meteorológicas e hídricas. Temperaturas mais elevadas, proporcionadas pelo aumento da incidência de radiação solar, podem aumentar a transpiração das plantas. Entretanto, ocorre até o momento em que o potencial hídrico da folha reduza, induzindo o fechamento estomático (Melo et al., 2010).

O objetivo deste trabalho foi determinar características fisiológicas e térmicas da canade-açúcar, em linhas orientadas ao Norte e Sul, no sub-bosque de canafístula (Peltophorum dubium Sprengel) em dois arranjos de plantas em sistema agroflorestal.

\section{Material e Métodos}

O estudo foi realizado em Frederico Westphalen - RS, com localização geográfica de $27^{\circ} 22^{\prime}$ S, $53^{\circ} 25^{\prime} \mathrm{W}$, a $480 \mathrm{~m}$ de altitude. Segundo a classificação climática de Köppen, o clima da região é Cfa, ou seja, subtropical úmido com temperatura média anual de $19,1^{\circ} \mathrm{C}$, variando com máximas de $38^{\circ} \mathrm{C}$ e mínimas de $0^{\circ} \mathrm{C}$.

O solo da área experimental é classificado como NEOSSOLO LITÓLICO Eutrófico típico pouco profundo (Cunha, 2011). Os valores das características químicas do solo foram: $\mathrm{pH}$ em água = 5,8; fósforo disponível $\left(\right.$ Mehlich $\left.^{-1}\right)=2,9$ $\mathrm{mg} \mathrm{dm}^{-3} ;$ alumínio $=0,0 \mathrm{cmol}_{\mathrm{c}} \mathrm{dm}^{-3} ;$ potássio $=82,5$ $\mathrm{mg} \mathrm{dm}{ }^{-3}$; cálcio $=8,7 \mathrm{cmol}_{\mathrm{c}} \mathrm{dm}^{-3}$ e magnésio $=2,8$ $\mathrm{cmol}_{\mathrm{c}} \mathrm{dm}^{-3}$. A adubação foi realizada conforme as recomendações para a cultura da cana-deaçúcar (Comissão de Química e Fertilidade do Solo, 2004).

O delineamento experimental utilizado foi de blocos completos casualizados, caracterizado por um esquema fatorial de $2 \times 2 \times 6$, ou seja, dois sistemas agroflorestais (faixa e linha), duas linhas de avaliação (Norte e Sul) e seis horários do dia $(9,10,12,14,15$ e 16 h), com três repetições.

O plantio da canafístula foi realizado em setembro de 2007 e a cana-de-açúcar (cultivar 
IAC87-3396) foi implantada em novembro de 2007, através do plantio manual das mudas e dos toletes, após a aração e gradagem da área. No sistema faixa (SF), a canafístula foi distribuída em faixas separadas por $12 \mathrm{~m}$, cada qual composta por três linhas, nas quais as plantas foram espaçadas em 3×3m. A cana-de-açúcar foi distribuída em oito linhas (entre as faixas, no espaço de $12 \mathrm{~m}$ ) e uma linha na faixa (entre as linhas de árvores).

No sistema linha (SL), o canafístula foi distribuída no espaçamento $6 \times 1,5 \mathrm{~m}$, ou seja, $6 \mathrm{~m}$ entre linha e 1,5m entre planta na linha, sendo a cana-de-açúcar distribuída em três linhas (entre as linhas das árvores). Em ambos os sistemas, a cana-de-açúcar apresentava espaçamento de $1,20 \mathrm{~m}$ e a densidade utilizada foi de 18 gemas por metro, sendo que, tanto as linhas da cana-de-açúcar quanto as das árvores foram orientadas no sentido Leste-Oeste. A disposição das árvores, da cana-de-açúcar e as linhas de avaliação estão demonstrados na figura 1.

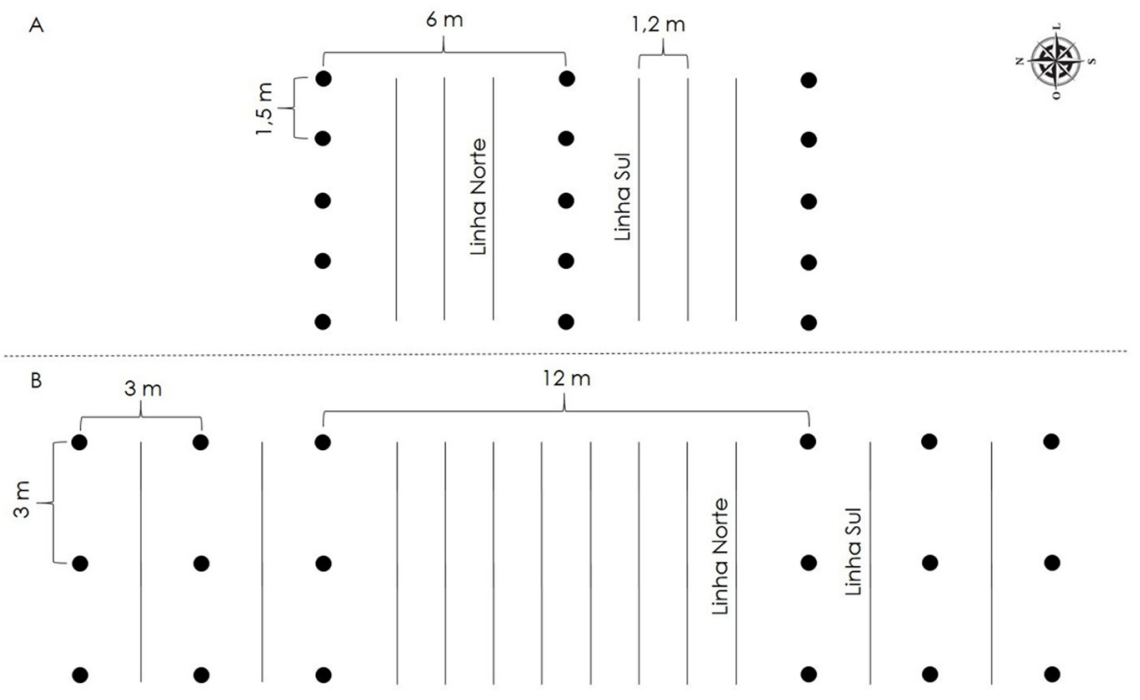

Figura 1. Croqui de uma unidade experimental dos sistemas Linha (A) e faixa (B). Círculos em cor preta representam as árvores de canafístula. Linhas contínuas indicam a cana-de-açúcar.

As características avaliadas foram: radiação fotossinteticamente ativa (RFA, $\mu \mathrm{mol}$ $\mathrm{s}^{-1} \mathrm{~m}^{-2}$ ) incidente, temperatura da folha $\left(\mathrm{TF},{ }^{\circ} \mathrm{C}\right)$, resistência à difusão de vapor (RS, $s \mathrm{~cm}^{-1}$ ) e transpiração $\left(E, m m o l ~ H_{2} O \mathrm{~s}^{-1} \mathrm{~m}^{-2}\right)$ ao longo de um dia, com uso de um porômetro digital LI1600 LI-COR. As avaliações foram realizadas na última folha totalmente expandida da cana-deaçúcar presente no centro das linhas avaliadas uma a norte e outra a sul, em cada unidade experimental.

No momento da avaliação, as árvores de canafístula apresentavam diâmetro à altura do peito (DAP) médio de 2,05 e 1,94 cm, altura média de 2,40 e 2,16 m e diâmetro médio da copa de 1,10 e 1,00 m, nos sistemas faixa e linha, respectivamente. Até o momento da avaliação, não foram realizadas práticas culturais no que se refere à condução da copa e ao desbaste das árvores.
As avaliações foram realizadas no dia 10/02/2009, aos 17 meses após o plantio, considerado dia típico em agroclimatologia. Esse dia foi escolhido por apresentar a abóboda celeste em condições de nebulosidade zero, permitindo assim, a obtenção dos máximos efeitos dos elementos meteorológicos sobre o ambiente de cultivo e, consequentemente, sobre as características analisadas. Este método foi utilizado por Caron et al. (2014a) em mudas de pata-de-vaca (Bauhinia forficata Link). Realizouse balanço hídrico da área experimental, utilizando-se capacidade de água disponível no solo (CAD) de $100 \mathrm{~mm}$, para verificar se houve deficiência hídrica durante o período de avaliação.

Os dados foram submetidos à análise de variância, por meio do programa computacional Statistical Analysis System Learning Edition 8.0 (SAS, 2003). Os parâmetros que demonstraram 
Elli et al. (2016) / Ecofisiologia da cana-de-açúcar no...

diferenças significativas através do teste $\mathrm{F}$ a nível de $5 \%$ de probabilidade de erro, foram comparados pelo teste de Tukey para os fatores sistema agroflorestal e linha de avaliação. Utilizou-se o teste de Bartlett para verificar a homogeneidade da variância.

\section{Resultados e Discussão}

De acordo o com balanço hídrico realizado para a área experimental, não observou-se deficiência hídrica durante o período de avaliação. A análise de variância revelou diferença na interação Hora do dia $x$
Sistema agroflorestal x Linha de avaliação para todas as variáveis analisadas (RFA, TF, RS, E).

No primeiro e último horário de avaliação (9 e 16h, respectivamente), a RFA foi superior na linha Sul nos sistemas faixa e linha. Nos outros horários não foi observada esta mesma resposta, onde a linha Norte apresentou os maiores valores, às $14 \mathrm{~h}$ no sistema faixa e, às 10 , 14 e 15h no sistema linha. Na comparação entre sistemas, o faixa, de modo geral, apresentou os maiores valores de RFA incidente na linha Sul, característica que variou de acordo com o horário na linha Norte (Figura 2).
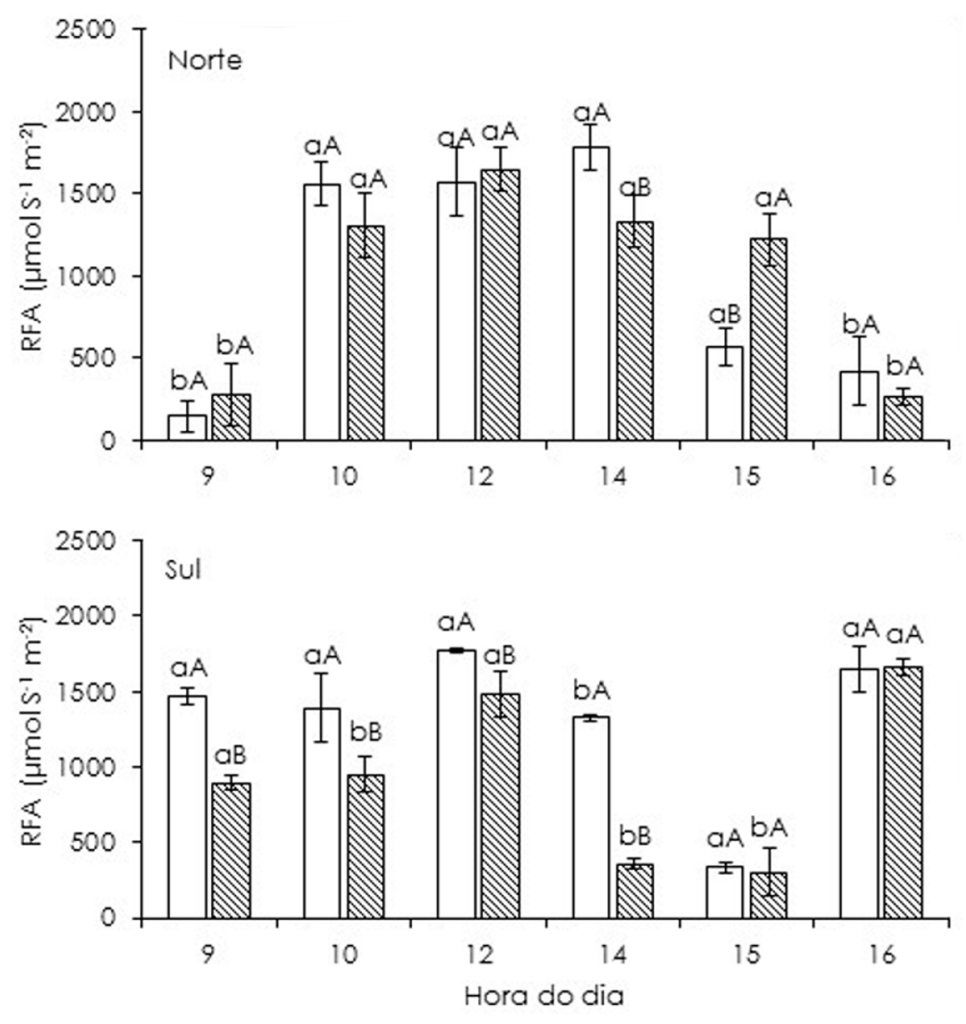

$\square$ Faixa \&Linho

Figura 2. Radiaçāo fotossinteticamente ativa (RFA) incidente na cana-de-açúcar no sub-bosque de canafístula em diferentes arranjos (faixa e linha) de sistema agroflorestal, nas linhas Norte e Sul, ao longo de um dia típico no município de Frederico Westphalen - RS. *Médias seguidas pela mesma letra, maiúscula comparando os sistemas agroflorestais Faixa e linha e minúscula comparando as linhas Norte e Sul, não diferem entre sí, pelo teste de Tukey a 5\% de probabilidade de erro $(p<0,05)$.

A dinâmica da RFA do sub-bosque de sistemas florestais ainda é pouco difundida em estudos científicos. As variações observadas estão relacionadas ao componente arbóreo do sistema (canafístula), principalmente o arranjo e as características morfológicas das plantas. A maior RFA incidente no sistema faixa ocorreu devido ao maior espaçamento entre árvores e entre as faixas ( $3 \times 3 \mathrm{~m}$ entre árvores e $12 \mathrm{~m}$ entre as faixas), comparado ao sistema linha.

Os maiores espaçamentos resultaram em menor quantidade de RFA interceptada pelo componente arbóreo, principalmente pela copa das árvores. A interceptação de RFA em 
espécies florestais foi relatada por Caron et al. (2012a), os quais encontraram os seguintes valores nas entre-linhas de plantio: $27,3 \% \mathrm{em}$ acácia negra (Acacia mearnsii De Wild); 56,3\% em bracatinga (Mimosa scabrella Benth) e $73,8 \%$ nas árvores de eucalipto (Eucalyptus grandis W. Hill ex Maiden), independente dos espaçamentos testados $(2,0 \times 1,0 ; 2,0 \times 1,5 ; 3,0$ $\times 1,0$ e $3,0 \mathrm{~m} \times 1,5 \mathrm{~m})$, todas as espécies com 1 ano de idade. Caron et al., (2014b) observaram valores de $85 \%$ para Pinus (Pinus elliotti Engelm.) com 34 anos de idade, altura média de $25,0 \mathrm{~m}$ e DAP de $50,3 \mathrm{~cm}$, sob espaçamento de $8 \times 8 \mathrm{~m}$.

De acordo com Caron et al., (2014a), estudando a variação da RFA no interior de ambiente protegido em um dia típico de verão, os valores desta variável aumentam até as $12 \mathrm{~h}$ e depois decrescem. Nos sistemas agroflorestais, em alguns horários de alta incidência de radiação solar ao longo do dia, a radiação é atenuada, como pode ser observado principalmente as $15 \mathrm{~h}$ na linha Sul, nos sistemas faixa e linha (Figura 2).

Esta variação ocorre devido à interação com o componente arbóreo. A canafístula apresenta ramificação dicotômica (ocorrência de brotação múltipla, provocando bifurcações no fuste da árvore), copa ampla, umbeliforme, largamente achatada e arredondada (Carvalho, 2003).

O diâmetro médio da copa foi semelhante nos arranjos faixa e linha $(1,10$ e $1,00 \mathrm{~m}$, respectivamente. Apesar do tamanho da copa ser reduzido em ambos os sistemas, estas características provavelmente foram responsáveis pela atenuação da radiação solar. $O$ aumento da radiação solar após às $15 \mathrm{~h}$ ocorreu devido à modificação da inclinação solar ao longo do dia, pelo aumento do ângulo zenital (formado entre o zênite local e a inclinação dos raios solares), uma vez que a projeção da copa demonstrou menor influência. Interessante ressaltar que a redução da RFA incidente na cana-de-açúcar não provocou o estiolamento das plantas.

A redução da quantidade de RFA incidente no sub-bosque dos sistemas agroflorestais acarretou modificações nas características térmicas e fisiológicas da cana- de-açúcar. A diferença da TF entre os sistemas faixa e linha foram pouco evidentes, entretanto a variação entre as linhas Norte e Sul foram expressivas. No sistema faixa, a linha Norte apresentou menor TF nos primeiros horários da manhã (9 e 10h) e maior TF no último horário de avaliação (16h) (Figura 3).

No sistema linha não foram observadas variações da TF entre as linhas de avaliação (Figura 3). Este resultado pode estar atrelado a menor incidência de RFA e menor variação destes valores ao longo do dia, uma vez que as árvores neste sistema estão mais próximas e interceptam uma maior quantidade de radiação solar. Resultados semelhantes foram encontrados por Caron et al. (2012b), ao constatar que uma maior densidade de plantas permite $\mathrm{O}$ fechamento mais rápido do dossel vegetativo, e consequentemente maior interceptação de RFA.

A RS no sistema faixa foi maior na linha Norte nos dois primeiros horários de avaliação. A linha Sul foi responsável pelos maiores valores às 16h. Na comparação entre sistemas, de modo geral, a RS foi superior no sistema faixa, exceto no primeiro horário de avaliação (Figura 4).

Esse resultado está atrelado à maior incidência de radiação no interior deste sistema. Caron et al. (2014a) constataram que, à medida em que a RFA aumenta, a RS também aumenta. Tal variação ocorre pelo fato das plantas de cana-de-açúcar realizarem o fechamento parcial dos estômatos em condições de alta incidência de RFA para evitar perdas excessivas de água por transpiração (Ding et al., 2006).

Entretanto, esse comportamento pode depender do tipo de metabolismo da espécie estudada e da intensidade de RFA. A cana-deaçúcar apresenta metabolismo C4, tendo alta eficiência fotossintética e ponto de saturação luminosa elevado (Barbieri, 1981). De acordo com Gazolla-Neto et al. (2013), altos valores de radiação solar, dependendo da espécie, podem prejudicar a eficiência quântica da fotossíntese, provocando a danificação do aparato fotossintético.

Em sistemas agroflorestais, a RFA se altera frequentemente no interior do dossel vegetativo, uma vez que o componente arbóreo é irregulare 

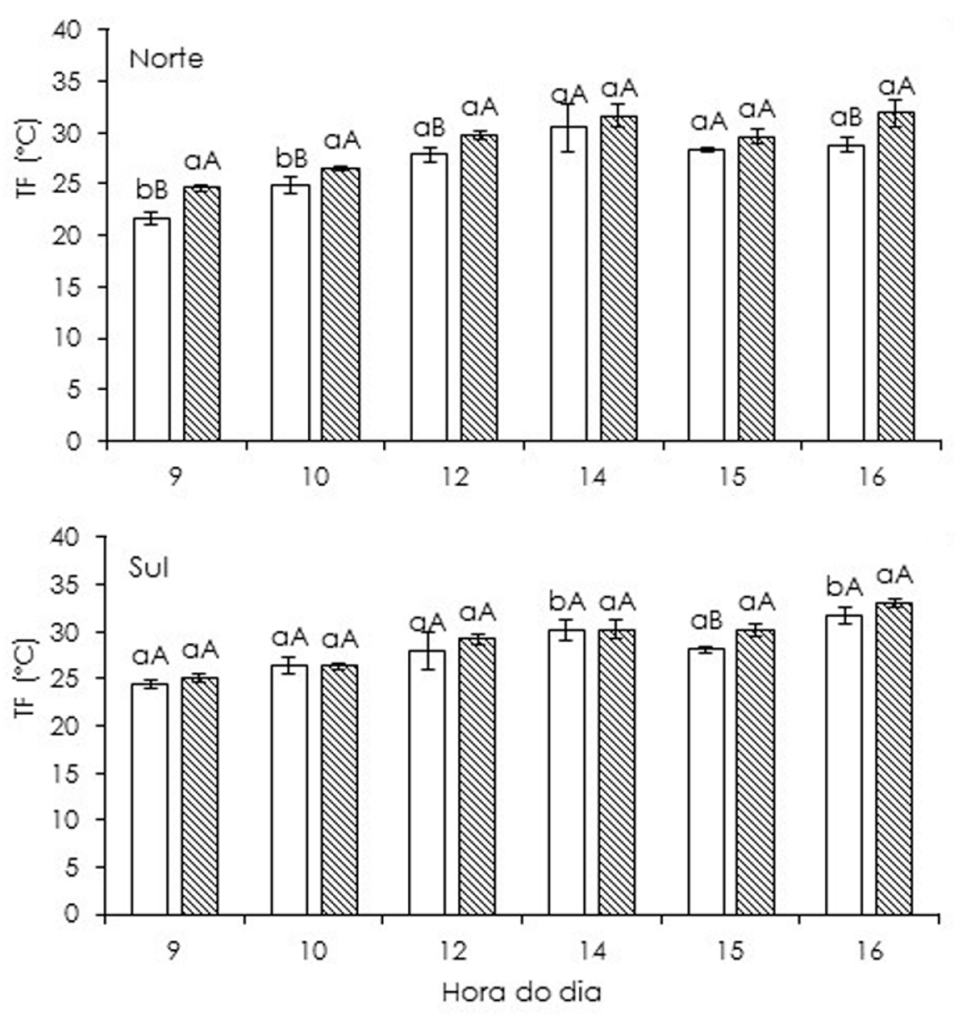

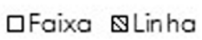

Figura 3. Temperatura da folha (TF) da cana-de-açúcar no sub-bosque de canafístula em diferentes arranjos (faixa e linha) de sistema agroflorestal, nas linhas Norte e Sul, ao longo de um dia típico no município de Frederico Westphalen RS. *Médias seguidas pela mesma letra, maiúscula comparando os sistemas agroflorestais Faixa e linha e minúscula comparando as linhas Norte e Sul, não diferem entre sí, pelo teste de Tukey a $5 \%$ de probabilidade de erro $(p<0,05)$.

mesmo sofre influência da ação dos ventos. Tais fatores acarretam a modificação da projeção de sombra das árvores, além da modificação do ângulo solar ao longo do dia.

A redução da RS devido à maior abertura estomática influenciou a ocorrência de um aumento da taxa transpiratória (E) da planta, a qual, de modo geral, foi maior no sistema linha (Figura 5).

Os resultados estão de acordo com aqueles encontrados por Elli et al. (2013) e Caron et al. (2014a), ao constatarem que na medida em que RS diminui, a E aumenta, principalmente em condições de baixa intensidade luminosa. Os valores transpiratórios mais elevados em ambientes sombreados podem estar associados à menor variação da umidade relativa do ar, característica comum a ambientes mantidos nessas condições (Souza et al., 2011). Neste contexto, Casaroli et al. (2010) relatam que a taxa de transpiração das folhas é diretamente influenciada pelo saldo de radiação, condutância estomática, e do déficit de saturação de vapor no ar.

Na comparação entre as linhas, às $10 \mathrm{~h}$ foram observados valores de E superiores na linha Sul, para o sistema faixa e às 14 h na linha Norte, para o sistema linha (Figura 5). A maior E nestes horários, diferentemente da variação entre os sistemas, foi motivada pelo aumento da RFA (Figura 2). Apesar dos valores de E serem maiores em ambientes sombreados, a RFA apresenta expressiva importância neste contexto. Entretanto, a resposta da RFA na transpiração pode não ser instantânea, uma vez que a quantidade de energia necessária para separar as moléculas de água da fase líquida e movê-las para a fase sólida (calor latente de vaporização da água), a $25^{\circ}$, é de $44 \mathrm{~kJ} \mathrm{~mol}^{-1}$ (Taiz \& Zeiger, 2013).

Isso demonstra que, para ocorrer a transpiração de água pelas folhas, é necessário 

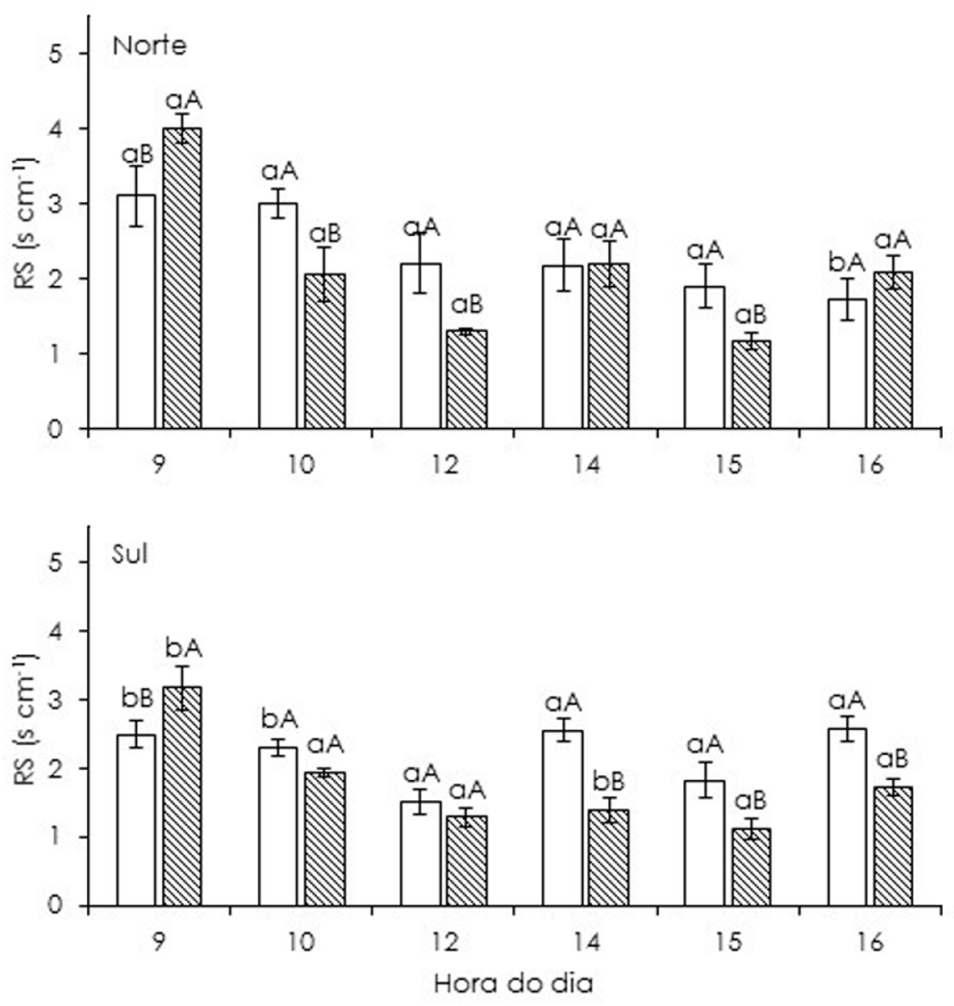

口Faixa \&Linho

Figura 4. Resistência à difusão de vapor (RS) das folhas de cana-de-açúcar no subbosque de canafístula em diferentes arranjos (faixa e linha) de sistema agroflorestal, nas linhas Norte e Sul, ao longo de um dia típico no município de Frederico Westphalen - RS. *Médias seguidas pela mesma letra, maiúscula comparando os sistemas agroflorestais Faixa e linha e minúscula comparando as linhas Norte e Sul, não diferem entre sí, pelo teste de Tukey a $5 \%$ de probabilidade de erro $(p<0,05)$.

o acúmulo de uma determinada quantidade de energia, provinda da radiação solar. Além disso, a maior incidência de RFA não reflete diretamente no aumento instantâneo da temperatura do ar (calor sensivel), sendo que é outra variável que pode modificar a temperatura da folha e consequentemente a $\mathrm{E}$.

Indiretamente, a modificação das características fisiológicas podem influenciar o crescimento, desenvolvimento e produtividade vegetal. Taiz \& Zeiger (2013) destacam que - fechamento estomático, que ocorre principalmente nas horas mais quentes do dia, prejudica a atividade fotossintética pelo fato de impedir a entrada de $\mathrm{CO}_{2}$, reduzindo a taxa de crescimento das culturas.

O conhecimento da dinâmica dos elementos meteorológicos existentes no interior de sistemas agroflorestais, bem como da resposta fisiológicas das plantas presentes no sub-bosque, podem ser úteis para a escolha de um correto planejamento, bem como dos tratos culturais e do espaçamento a ser utilizado para o componente arbóreo do sistema. Novas pesquisas devem ser realizadas com outras espécies, tanto arbóreas, quanto anuais, para maiores esclarecimentos e a inserção de novas alternativas neste ramo de estudo. 

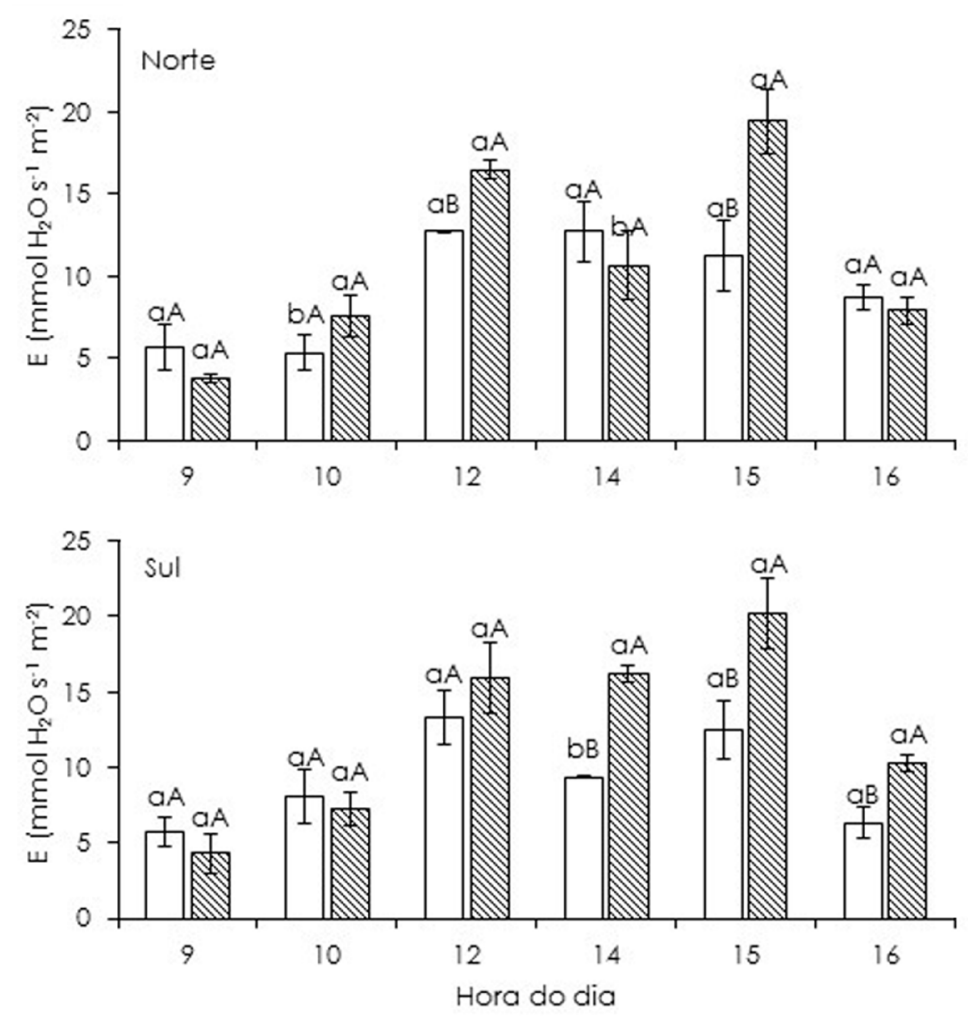

口Faixa \&Linha

Figura 5. Transpiraçāo (E) das folhas da cana-de-açúcar no sub-bosque de canafístula em diferentes arranjos (faixa e linha) de sistema agroflorestal, nas linhas Norte e Sul, ao longo de um dia típico no município de Frederico Westphalen - RS. *Médias seguidas pela mesma letra, maiúscula comparando os sistemas agroflorestais Faixa e linha e minúscula comparando as linhas Norte e Sul, não diferem entre sí, pelo teste de Tukey a $5 \%$ de probabilidade de erro $(p<0,05)$.

\section{Conclusões}

As características fisiológicas e térmicas da cana-de-açúcar são influenciadas pelo arranjo de árvores do sistema agroflorestal e pelo local de avaliação dentro do sistema.

O sistema faixa, de modo geral, apresenta maior quantidade de radiação fotossinteticamente ativa disponível em seu subbosque, o que reflete em aumento dos valores de resistência à difusão de vapor e redução da transpiração da cana-de-açúcar.

A linha Sul apresenta maior transpiração da cana-de-açúcar pela manhã no sistema faixa e menor à tarde, no sistema linha, devido aos maiores valores de temperatura da folha.

\section{Referências}

Barbieri, V. 1981. Medidaseestimativas de consumo hídrico em cana-de-açucar (Saccharum spp.). 142f. (Dissertação de Mestrado) Universidade de São Paulo, Piracicaba, Brasil.
Caron, B.O., Lamego, F.P., Souza, V.Q. de, Costa, E.C., Eloy, E., Behling, A., Trevisan, R. 2012a. Interceptação de radiação luminosa pelo dossel de espécies florestais e sua relação com o manejo de plantas daninhas. Ciência Rural 42: 75-82.

Caron, B.O., Perrando, E.R., Schmidt, D., Manfron, P.A., Behling, A., Elli, E.F., Eloy, E. 2014a. Relações fisiológicas em mudas de pata-de-vaca (Bauhinia forficata Link). Revista Brasileira de Plantas Medicinais 16: 196-201.

Caron, B.O., Schmidt, D., Manfron, P.A., Behling, A., Eloy, E. Busanello, C. 2014b. Eficiência do uso da radiação solar por plantas llex paraguariensis A. ST. HIL. cultivadas sob sombreamento e a pleno sol. Ciência Florestal 24: 257-265.

Caron, B.O., Souza, V.Q.D., Trevisan, R., Schmidt, D., Behling, A., Bamberg, R., \& Eloy, E. 2012b. Eficiência de conversão da radiação fotossinteticamente ativa interceptada em fitomassa de mudas de eucalipto. Revista Árvore 36: 833-842.

Carvalho, P.E.R. 2003. Espécies arbóreas 
brasileiras. 2. ed. Embrapa Informação Tecnológica; Embrapa Florestas, Brasília; Colombo, Brasil. 1036p.

Casaroli, D., Van Lier, Q.D.J., Irigoyen, A.I., Simon, J., Scarpare, F.V. 2010. Estimativa da taxa de transpiração do feijoeiro a partir de medidas de porometria, em diferentes camadas do dossel. Revista Brasileira de Agrometeorologia 16: 49153.

Comissão de Química E Fertilidade do Solo (CQFS) RS/SC. Manual de adubação e calagem para os estados do Rio Grande do Sul e Santa Catarina. 2004. Sociedade Brasileira de Ciência do Solo - Núcleo Regional Sul, Porto Alegre, Brasil. 400p.

Cunha, N.G., Silveira, R.J.C., Koester, E., Oliveira, L.D., Alba, J.M.F., Terres, V.C., Lopes, R.T. 2011. Estudos de Solos do Município de Frederico Westphalen, RS. EMBRAPA. Pelotas, Brasil. 32 p. (Circular Técnica 116).

Ding, L., Wang, K.J., Jiang, G.M., Li, Y.M., Jiang, C.D., Liu, M.Z., Niu, S.L., PENG, Y. 2006. Diurnal variation of gas exchange, chlorophyll fluorescence and xanthophyll cycle components of maize hybrids released in different years. Photosynthetica 44: 26-31.

Elli, E.F., Caron, B.O., Monteiro, G.C., Pavan, M.A., Pedrassani, M., Cantarelli, E.B., Eloy, E. 2013. Osmocote no desenvolvimento e comportamento fisiológico de mudas de pitangueira. Comunicata Scientiae 4: 377-384.

Gazolla-Neto, A., Aumonde, T.Z., Pedó, T., Olsen, D., Villela, F.A. 2013. Ação de níveis de luminosidade sobre o crescimento de plantas de maria-pretinha (Solanum americanum Mill.). Revista Brasileira de Biociência 11: 88-92.

Melo, A.D., Suassuna, J.F., Fernandes, P.D., Brito, M.E.B., Suassuna, A.F., Aguiar Netto, A.D.O. 2010. Crescimento vegetativo, resistência estomática, eficiência fotossintética e rendimento do fruto da melancieira em diferentes níveis de água. Acta Scientiarum. Agronomy 32: 73-79.

Mendes, M.M.S.; Lacerda, C.F.; Cavalcante, A.C.R.; Fernandes, F.É.P.; Oliveira, T.S. 2013. Desenvolvimento do milho sob influência de árvores de pau branco em sistema agrossilvipastoril. Pesquisa Agropecuária Brasileira 48: 1342-1350.

Muller, M., Paciullo, D.S.C., Martins, C.E., Rocha, W.S.D., Castro, C.R.T. 2014. Desenvolvimento vegetativo de pinhão-manso em diferentes arranjos de plantio em sistemas agrossilvipastoris. Pesquisa Agropecuária Brasileira 9: 506-514.

Neves, C.M.N., Silva, M.L.N., Curi, N., Macedo, R.L.G., Moreira, F.M. de S., D'Andréa, A.F. 2009.
Indicadores biológicos da qualidade do solo em sistema agrossilvipastoril no noroeste do Estado de Minas Gerais. Ciência e Agrotecnologia 33: 05-112.

Paciullo, D.S., Gomide, C.A., Castro, C.R., Fernandes, P.B., Müller, M.D., Pires, M.F., Fernandes, E.N., Xavier, D.F. 2011. Características produtivas e nutricionais do pasto em sistema agrossilvipastoril, conforme a distância das árvores. Pesquisa Agropecuária Brasileira 46: $1173-1186$.

Salton, J.C., Mercante, F.M., Tomazi, M., Zanatta, J.A., Concenço, G., Silva, W.M., Retore, M. 2013. Integrated crop-livestock system in tropical Brazil: toward a sustainable production system. Agriculture, Ecosystems and Environment 1:70-79.

SAS LEARNING EDITION. Getting started with the SAS Learning Edition. Cary. 200p, 2003.

Souza, C.D., Fernandes, D.P., Barroso, M.R., Portes, T.A. 2011. Transpiração de espécies típica do cerrado medida por transpirômetro de equilíbrio e porômetro. Cerne 17: 509-515.

Taiz, L., Zeiger, E. 2013. Fisiologia Vegetal. 5. ed. Artmed, Porto Alegre, Brasil. 918p.

Tracy, B.F., Zhang, Y. 2008. Soil compaction, corn yield response, and soil nutrient pool dynamics within an integrated crop-livestock system in Illinois. Crop Science 48: 1211-1218.

Xavier, D.F., Lédo, F.J. da S., Paciullo, D.S. de C., Urquiaga, S., Alves, B.J.R., Boddey, R.M. 2014. Nitrogen cycling in a Brachiaria-based silvopastoral system in the Atlantic forest region of Minas Gerais, Brazil. Nutrient Cyclingin Agroecosystems 99: 45-62. 